\title{
Changes of Antioxidant Defense System and Fatty Acid Composition in Bermudagrass under Chilling Stress
}

\author{
Zhengrong Hu, Erick Amombo, Margaret Mukami Gitau, and Aoyue Bi \\ Key Laboratory of Plant Germplasm Enhancement and Specialty Agriculture and Wuhan Botanical \\ Garden, Chinese Academy of Sciences, Wuhan, Hubei 430074, People's Republic of China; and \\ University of Chinese Academy of Sciences, 19 Yuquan Road, Beijing 100049, People's Republic \\ of China
}

\author{
Huihui Zhu \\ College of Resources and Environmental Science, South-Centre University for Nationalities, Wuhan, \\ Hubei 430074, People's Republic of China
}

\begin{abstract}
Liang Zhang
Key Laboratory of Plant Germplasm Enhancement and Specialty Agriculture and Wuhan Botanical Garden, Chinese Academy of Sciences, Wuhan, Hubei 430074, People's Republic of China; and University of Chinese Academy of Sciences, 19 Yuquan Road, Beijing 100049, People's Republic of China
\end{abstract}

\section{Liang Chen ${ }^{1}$ and Jinmin Fu ${ }^{1}$ \\ Key Laboratory of Plant Germplasm Enhancement and Specialty Agriculture and Wuhan Botanical Garden, Chinese Academy of Sciences, Wuhan, Hubei 430074, People's Republic of China}

\begin{abstract}
AdDitional INDEX words. low temperature, genotype, glutathione, gene expression, reactive oxygen species
Abstract. Bermudagrass (Cynodon dactylon) is a typical and widely used warm-season turfgrass. Low temperature is one of the key environmental stress limiting its utility. However, little information is available about the differences of cold response between bermudagrass genotypes. Here, we analyzed antioxidant defense system and fatty acid composition in cold-resistant genotype WBD128 and cold-sensitive genotype WBDg17 exposed to chilling stress. Low temperature $\left(4^{\circ} \mathrm{C}\right)$ significantly decreased the relative water content, whereas increased the $\mathrm{H}_{2} \mathrm{O}_{2}$ and $\mathrm{O}_{2}{ }^{-}$contents, more profoundly for WBDg17. Under chilling condition, WBD128 had higher anti $\mathrm{O}_{2}^{-}$activity than WBDg17. Besides, the contents of total glutathione, reduced glutathione (GSH) and its oxidized form (GSSG) were markedly increased by low temperature in both genotypes, whereas WBD128 had significantly higher values of GSH, total glutathione, and GSH/GSSG ratio than WBDg17. Moreover, chilling stress increased saturated fatty acids (SFAs) percentage (palmitic acid and stearic acid) in WBDg17. After chilling treatment, the proportion of linoleic acid decreased in both genotypes, particularly in WBDg17. As for unsaturated fatty acids (UFAs), the percentage of linolenic acid was increased in WBD128. In addition, chilling treatment decreased the values of double bond index (DBI), UFA/SFA ratio as well as degree of unsaturation in WBDg17. Finally, chilling stress altered the expression patterns of the genes, which encode one kind of late embryogenesis abundant proteins $(L E A)$, superoxide dismutase $(C u / Z n S O D) C$-repeat-binding factor/DRE-binding factor $(C B F 1)$, and peroxidase (POD-2). Collectively, our results revealed that natural variation of chilling tolerance in bermudagrass genotypes may be largely associated with the alterations of antioxidant defense system and fatty acid composition.
\end{abstract}

Low temperature is one of the most detrimental abiotic stresses, which limits plant growth and productivity as well as distribution (Burke et al., 1976). The mechanisms of coldinduced injury are complex, and vary across different species and hardness degree (Baek and Skinner, 2003; Burke et al., 1976; Iswari and Palta, 1989). The status of the plasma membrane is crucial to cellular response when a plant is exposed to cold stress (Thomashow, 1999). Numerous mechanisms have been proposed to be involved in membrane damage under cold stress.

Received for publication 29 Nov. 2016. Accepted for publication 17 Feb. 2017. This work was funded by the China National Science Foundation (NSFC) (grant nos. 31272194, 31401915, and 31428021). We would like to thank Qian Liu for collecting the documents.

${ }^{1}$ Corresponding authors. E-mail: jfu@wbgcas.cn or chenliang1034@126.com.
This includes structural transitions and membrane phase transitions (Pearce and Willison, 1985), injury to membranebound ATPase (Iswari and Palta, 1989), and loss of bound water (Weiser, 1970).

Oxidative stress also has been suggested to be one of the causes of cold-induced damage (Halliwell and Gutteridge, 2015; McKersie and Bowley, 1997), which occurs when there are excessive free cellular radicals. Under normal condition, reactive oxygen species (ROS) are generated on a regular basis and at a low level (Arora et al., 2002). When plants are subjected to stresses, excessive ROS are produced, which can induce plant injury, including peroxidation of cell membrane components, enzymes denaturation, and DNA strands distortion (Halliwell and Gutteridge, 2015). To alleviate the detrimental effects of oxidative stress, plants have developed 
various and effective antioxidant systems necessary for scavenging ROS (Mittler, 2002), including enzymes and nonenzymatic antioxidants; for example, L- $\gamma$-glutamyl-L-cysteinyl-glycine. Antioxidant enzymes and nonenzymatic antioxidants were generally induced by stresses, and the elevated activities enhanced resistance to stress (Allen, 1995). Glutathione and glutathione reductase has been reported to participate in the redox regulation, as components of the ascorbate-glutathione cycle (Foyer et al., 1997). Under chilling conditions, the ratio of GSH to glutathione disulfide decreases. It is because that GSH is used for the reduction of excess $\mathrm{H}_{2} \mathrm{O}_{2}$ in the ascorbate-glutathione cycle (Foyer et al., 1997). Besides, the increase of $\mathrm{H}_{2} \mathrm{O}_{2}$ and the succeeding changes of the GSH/GSSG ratio may serve as signals to activate specific transcription factors and antioxidant enzymes (Kocsy et al., 2001). In addition, GSH is involved in numerous physiological processes in plants, which include control of cell division and gene expression (Noctor et al., 1998), transport and storage of sulfur (Rennenberg and Brunold, 1994), and removal of toxic metabolite by the formation of glutathione $\mathrm{S}$ (GS) conjugates (Mauch and Dudler, 1993). Changes in the GSH content and GSH/GSSG ratio may modulate these physiological processes in plants' response to the unfavorable environmental conditions.

Fatty acids can be divided into SFAs and UFAs. UFAs have double bonds (one or more), and more common cis-double bonds help maintain membrane fluidity, which is pivotal for plant survival during cold stress (Cyril et al., 2002; Lehninger, 1977; Vigh et al., 1998). Causally, under cold stress, cellular membranes undergo a phase transition from liquid crystalline (highly fluid) to gel phase (more rigid). In the gel phase, lipids are highly ordered, which hampers regular physiological functions, and makes the cellular membrane more permeable (Cyril et al., 2002). Multiple biochemical and biophysical alterations occur to prevent the phase transition. In addition, the degree of unsaturation dramatically impacts the temperature range in which cell membrane undergo pernicious phase change (Vigh et al., 1998). Thus, increasing the percentage of UFA in membrane fatty acid composition contributes to the maintenance of plasma membrane stability, integrity, as well as function (Steponkus, 1984).

Bermudagrass is a typical warm-season turfgrass species, which grows in warm climatic regions and exhibits remarkably great stress resistance. This turfgrass has been widely applied on account of its superior merits of fast reproduction and traffic tolerance, particularly in parks, sport fields, and lawns (Fan et al., 2014; $\mathrm{Hu}$ et al., 2016a; Shi et al., 2014; Zhang et al., 2008). As a warm-season turfgrass, the optimum temperature for growth is 26 to $35^{\circ} \mathrm{C}$, and low temperature is considered as a key environmental factor limiting bermudagrass growth and utility (Fan et al., 2014). However, limited research has been done on chilling resistance in bermudagrass. Therefore, detailed information about chilling stress response in bermudagrass is urgent and crucial for grass engineering (Fagerness et al., 2002; Shi et al., 2014; Zhang et al., 2008, 2011a, 2011b).

This study was designed to investigate the differences of chilling stress response between the cold-sensitive bermudagrass genotype WBDg17 and the cold-resistant genotype WBD128, and explore the possible mechanisms involved in chilling stress response in bermudagrass. Several physiological indicators, combined with fatty acid composition and gene expression patterns were investigated.

\section{Materials and Methods}

Plant material and growth conditions. Two wild types of bermudagrass, WBDg17 and WBD128, used in the study had been selected by some colleagues in our laboratory and have been reported by Chen et al. (2010). Initially, 128 bermudagrass accessions were used in the screening test. The plants were treated with $4{ }^{\circ} \mathrm{C}$ for $21 \mathrm{~d}$, and the control was maintained at $\left(30{ }^{\circ} \mathrm{C}\right.$ day $/ 25^{\circ} \mathrm{C}$ night). Several parameters were determined every week including transpiration rate and growth rate. After the first round of screening, 10 relatively cold-tolerant and coldsensitive accessions were selected. The selected accessions were then treated with $-5^{\circ} \mathrm{C}$ for $4 \mathrm{~h}$ to further screen for the relatively most cold-tolerant and cold-sensitive genotypes. Finally, the most promising cold-tolerant and cold-sensitive bermudagrass genotypes were selected. The cold-sensitive (S) genotype WBDg17 was collected from Xiaojiang City, Zhejiang Province, China (lat. $27^{\circ} 34.258^{\prime} \mathrm{N}$, long. $\left.120^{\circ} 27.383^{\prime} \mathrm{E}\right)$, whereas the cold-resistant (R) genotype WBD128 was collected from Baise City, Guangxi Province, China (lat. $24^{\circ} 51.397^{\prime} \mathrm{N}$, long. $106^{\circ} 33.288^{\prime} \mathrm{E}$ ). Uniform stolons of the two genotypes were planted in plastic pots $(7.5 \mathrm{~cm}$ diameter and $9.0 \mathrm{~cm}$ deep) filled with matrix (brown coal soil) (on 5 Apr. 2016). These pots were kept in the greenhouse for 2 months to establish, with growth conditions of (light/dark) $12 / 12 \mathrm{~h}$, $30 / 25^{\circ} \mathrm{C}, 240 \mu \mathrm{mol} \cdot \mathrm{m}^{-2} \cdot \mathrm{s}^{-1}$, and $60 \%$ relative humidity $(5 \mathrm{Apr}$. to 5 June 2016). During this period, plants were watered every $2 \mathrm{~d}$ and fertilized weekly with half-strength Hoagland's solution (Hoagland and Arnon, 1950), and the plants were not mowed.

Treatments. All established bermudagrass were transferred to growth chambers (HP300GS-C; Wuhan Ruihua Instrument and Equipment Co., Wuhan, China) for $3 \mathrm{~d}$ of adaptation, with conditions of (light/dark) $12 / 12 \mathrm{~h}, 30 / 25^{\circ} \mathrm{C}, 240 \mu \mathrm{mol} \cdot \mathrm{m}^{-2} \cdot \mathrm{s}^{-1}$, and $60 \%$ relative humidity. And the lights they used were cold light illuminators. On 8 June 2016, plants were subjected to two temperature treatments: the control and chilling treatment, which were performed by two growth chambers. For control chamber, the conditions were (light/dark) $12 / 12 \mathrm{~h}, 30 / 25^{\circ} \mathrm{C}$, $240 \mu \mathrm{mol} \cdot \mathrm{m}^{-2} \cdot \mathrm{s}^{-1}$, and $60 \%$ relative humidity, whereas chillingtreated chamber were $12 / 12 \mathrm{~h}, 4 / 4{ }^{\circ} \mathrm{C}, 240 \mu \mathrm{mol} \cdot \mathrm{m}^{-2} \cdot \mathrm{s}^{-1}$, and $60 \%$ relative humidity. Low temperature $\left(4^{\circ} \mathrm{C}\right)$ was selected according to many previous studies (Fan et al., 2014; Hu et al., 2016a, 2016b; Shi et al., 2014) and the initial screening test of bermudagrass (unpublished data). Actually, the day temperature and the night temperature were 4.9 to $5.6^{\circ} \mathrm{C}$ and 4.3 to $4.6{ }^{\circ} \mathrm{C}$, respectively, in the growth chambers for the cold treatment. Plants of each species were subjected to the two treatments for a week ( 8 to 15 June 2016). During the treatment period, fully extended bermudagrass leaves were collected at $0,3,6,12,24$, and $48 \mathrm{~h}$ for RNA extraction, and at $7 \mathrm{~d}$ for measurements of RWC, enzyme activity, ROS, and fatty acids.

Measurements. RWC was determined on 16 June 2016 according to the method described by Barrs and Weatherley (1962) with slight modifications. In brief, leaves were clipped and weighed [fresh weight (FW)], then transferred into small petri dishes filled with deionized water. The leaves were soaked in water for $24 \mathrm{~h}$ at $25^{\circ} \mathrm{C}$, thereafter the leaves were weighed after removal of excessive moisture by blotting paper [turgid weight (TW)]. Subsequent drying of leaves was done at $70{ }^{\circ} \mathrm{C}$ for $24 \mathrm{~h}$ to measure dry weight (DW). Leaf RWC was calculated following the formula: $(\mathrm{FW}-\mathrm{DW}) /(\mathrm{TW}-\mathrm{DW}) \times$ 100 . 
Crude enzyme extraction was performed on 17 June 2016 according to Fan et al. (2014). Fully expanded leaves (0.2 g) were grounded into powder in liquid nitrogen, and then the powder was transferred into $15-\mathrm{mL}$ tubes filled with $4 \mathrm{~mL}$ sodium phosphate buffer (150 mm, pH 7.0). After $5 \mathrm{~h}$ extraction at $4{ }^{\circ} \mathrm{C}$, the extraction solution was centrifuged for $25 \mathrm{~min}$ at $8000 \mathrm{~g}_{\mathrm{n}}$ at $4{ }^{\circ} \mathrm{C}$. The supernatant was decanted into 2-mL microcentrifuge tubes for the subsequent physiological assays.

The ROS contents were measured on 18 June 2016 by using different kits. The measurements of $\mathrm{H}_{2} \mathrm{O}_{2}$ and $\mathrm{O}_{2}{ }^{-}$concentrations were, respectively, performed by using $\mathrm{H}_{2} \mathrm{O}_{2}$ assay kits (A064; Nanjing Jiancheng Bioengineering Institute, Nanjing, China), and Plant $\mathrm{O}_{2}{ }^{-}$ELISA Kit (10-40-488; Bejing Dingguo, Beijing, China) according to the manufacturer's instructions as introduced by Shi et al. (2013). The anti- ${ }_{2}^{-}$activity was measured by using the assay kit (A052; Nanjing Jiancheng Bioengineering Institute). For the anti $\mathrm{O}_{2}{ }^{-}$activity determination, the electron transport material and chromogenic agent were added to react with superoxide anion free radical, which produced by the system of xanthine and xanthine oxidase. After chemical reaction, the red mixture was quantified at 550 $\mathrm{nm}$ of absorbance. Moreover, the concentrations of $\mathrm{GSH}$, GSSG, and total glutathione were determined by using the GSH and GSSG Assay Kit (S0053; Beyotime, Shanghai, China) in accordance with the manufacturer's instructions as described by Shi et al. $(2013,2014)$. The GSH/GSSG ratio was calculated based on GSH and GSSG concentration.

Total lipid was extracted from bermudagrass leaves on 20 June 2016 by using the method described by Mishra et al. (2015) with some modifications. About $0.3 \mathrm{~g}$ bermudagrass leaves were ground into fine powder and then extracted in $10 \mathrm{~mL}$ chloroform-methanol-phosphate buffer $(1: 2: 0.9 \mathrm{v} / \mathrm{v} / \mathrm{v}$, $\mathrm{pH} 7.5)$. Then $50 \mathrm{~mL}$ of $2 \mathrm{mg} \cdot \mathrm{mL}^{-1}$ heptadecanoic acid (C17:0 as internal standard) was added. The homologous fatty acid methyl esters (FAMEs) of these fatty acids were obtained by transmethylation (Kumari et al., 2013). Transmethylation was conducted by adding $1 \mathrm{~mL}$ of $\mathrm{NaOH}(1 \% \mathrm{v} / \mathrm{v}$ in methanol) in a $15-\mathrm{mL}$ tube that contained extracted lipid, the mixture was thereafter heated at $55{ }^{\circ} \mathrm{C}$ for $15 \mathrm{~min}$. Thereafter, $2 \mathrm{~mL}$ of methanolic $\mathrm{HCl}(5 \% \mathrm{v} / \mathrm{v})$ was added followed by heating at $55^{\circ} \mathrm{C}$ for $15 \mathrm{~min}$, then the mixture solution was added with $3 \mathrm{~mL}$ of ultrapure water-hexane mixture $(1: 2 \mathrm{v} / \mathrm{v})$. These derivative FAMEs were extracted in hexane three times and dried with application of a bench-top centrifugal concentrator (Centrivap; Labogene, Lynge, Denmark). Finally, the dried extraction was dissolved in $200 \mu \mathrm{L}$ of hexane.

The fatty acids were determined by using gas chromatographymass spectrometer [GC-MS (7890A/5975C; Agilent Technologies, Palo Alto, CA)]. In brief, $200 \mu \mathrm{L}$ of derivative solution was transferred into a DB-5MS capillary $(30 \mathrm{~m} \times 0.25 \mathrm{~mm} \times 0.25 \mathrm{~mm}$; Agilent Technologies). The GC-MS was programmed as follows: the initial $\mathrm{GC}$ oven temperature was at $70^{\circ} \mathrm{C}$ for $2 \mathrm{~min}$, then from 70 to $230{ }^{\circ} \mathrm{C}$ with $3{ }^{\circ} \mathrm{C} \cdot \mathrm{min}^{-1}$ increment and $230{ }^{\circ} \mathrm{C}$ maintained for $10 \mathrm{~min}$, and subsequently, from 230 to $270{ }^{\circ} \mathrm{C}$ with $10^{\circ} \mathrm{C} \cdot \mathrm{min}^{-1}$ increase, and then held for $10 \mathrm{~min}$. Injection volume was $1 \mu \mathrm{L}$, helium was used as the carrier gas, and the flow rate was set at $1 \mathrm{mg} \cdot \mathrm{mL}^{-1}$. The determination was carried out by electron impact ionization at $70 \mathrm{eV}$ in the full scan mode $(\mathrm{m} / \mathrm{z} 30-650)$. The samples of bermudagrass were quantified against an internal standard (100 $\mu \mathrm{g}$ heptadecanoic acid), and the content of each fatty acid was expressed as a proportion of the total fatty acids present in the sample. The DBI was calculated by using the formula: Index $=(16: 1)+(18: 1)+2[(16: 2)+(18: 2)]+3[(18: 3)]$ (Larkindale and Huang, 2004). Parentheses indicate the proportion of the total fatty acid amount, which was composed of each fatty acid species.

For analysis of real-time quantitative reverse transcriptase polymerase chain reaction ( $\mathrm{qRT}$-PCR), total RNA in bermudagrass leaves was isolated and purified with application of Trizol reagent (Invitrogen, Carlsbad, CA) according to the method we described earlier (Hu et al., 2016a). RNA (about $2.5 \mu \mathrm{g}$ ) was reversely transcribed by using M-MLV reverse transcriptase (Promega, Madison, WI) and oligo (dT) primers following the operation manual. Expressions of the selected genes in treated bermudagrass leaves were analyzed by qRT-PCR with application of the fluorescent intercalating dye SYBR Green and StepOnePlus ${ }^{\mathrm{TM}}$ Real-Time PCR System (Applied Biosystems, Foster City, CA) for detection. The genespecific primers of selected genes listed in Table 1 were synthesized based on previously reported sequences, whereas an $A C T I N$ was used as the standard control in the reaction. The RT-PCR procedure was performed according to the method described by Chen et al. (2010).

Statistical Analysis. Three biological replicates were used in all the experiments, and values were given as mean $\pm \mathrm{SD}$. Statistical analyses were performed by one-way analysis of variance combined with independent-samples $t$ test. Means were separated at a significant level of $P<0.05$, by using the statistical package SPSS (version 16.0; IBM Corp., Armonk, NY), as well as Excel (2010 for Windows; Microsoft Corp., Redmond, WA).

\section{Results}

Physiological response to Chilling stress. As shown in Fig. 1, there was no significant difference in RWC between the two genotypes under control conditions. However, after $7 \mathrm{~d}$ of chilling treatment the values were decreased by $11.33 \%$ and $2.76 \%$ in the cold-sensitive genotype WBDg17 and coldtolerant genotype WBD128, respectively. This result indicated that leaves of WBDg17 lost water more than WBD128. Consistently, a better growth condition was also observed in the WBD128 (Supplemental Fig. 1).

Table 1. Genes (POD-2, SOD, $L E A$, and $C B F 1)$ involved in response to chilling stress in cold-resistant bermudagrass genotype WBD128 and cold-sensitive genotype WBDg 17 under chilling stress $\left(4{ }^{\circ} \mathrm{C}\right)$ and their forward and reverse primer sequences.

\begin{tabular}{lll}
\hline Gene $^{\text {name }}{ }^{\mathrm{z}}$ & & \multicolumn{1}{c}{ Primer sequences $\left(5^{\prime}-3^{\prime}\right)^{\mathrm{y}}$} \\
\hline$P O D-2$ & $\mathrm{~F}$ & AGGCAGCGGGGCTGAAGAAGG \\
& $\mathrm{R}$ & CCCTGACGAAGCAGTCGTGGAA \\
SOD & $\mathrm{F}$ & TGGGAAACATTGTTGCCAACA \\
& $\mathrm{R}$ & GCCAACAACACCACATGCCA \\
LEA & $\mathrm{F}$ & TCATCCCCAGCGTGTTCATCA \\
& $\mathrm{R}$ & GAGGCCGCCAAACAGAAGACA \\
CBF1 & $\mathrm{F}$ & ACCAAGTTCCGCGAGACGC \\
& $\mathrm{R}$ & CGAGTCGGCGAAGTTGAGGCA
\end{tabular}

${ }^{\mathrm{z}} P O D-2=$ gene that encodes one kind of peroxidase; $\mathrm{SOD}=$ gene that encodes one kind of superoxide dismutase; $L E A=$ gene that encodes one kind of late embryogenesis abundant proteins; $C B F 1=$ gene that encodes one kind of C-repeat-binding factor/DRE-binding factor.

${ }^{\mathrm{y}}$ Primer sequences. F and R represent forward and reverse, respectively. 


\section{$\square C K \square$ Chilling}

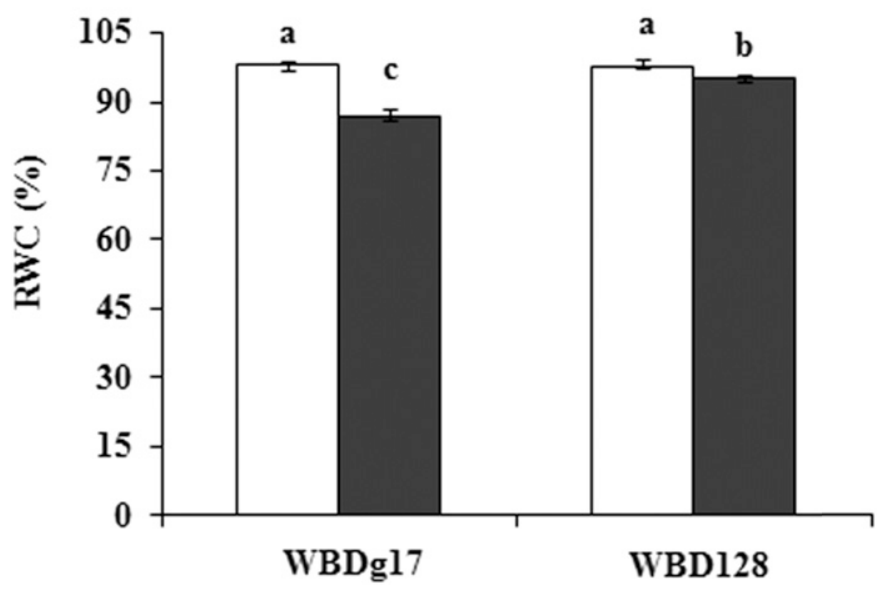

Fig. 1. Change of relative water content (RWC) in cold-resistant bermudagrass genotype WBD128 and cold-sensitive genotype WBDg17 under chilling stress. CK was the control with (light/dark) $12 / 12 \mathrm{~h}$ and $30 / 25^{\circ} \mathrm{C}$. Chilling represented (light/dark) $12 / 12 \mathrm{~h}$ and $4 / 4{ }^{\circ} \mathrm{C}$ conditions. All the regimes were treated for $7 \mathrm{~d}$. Mean values and SD were calculated from three biological repeats. Different letters represented statistical difference significant among different regimes by Duncan's multiple range tests $(P<0.05)$.

$\mathrm{H}_{2} \mathrm{O}_{2}$ and $\mathrm{O}_{2}^{-}$are two components of ROS, which if produced in excess is harmful for plant. In the study, there were no differences in $\mathrm{H}_{2} \mathrm{O}_{2}$ and $\mathrm{O}_{2}{ }^{-}$concentrations between the two genotypes under normal condition (Fig. 2A and $\mathrm{B}$ ). However, when exposed to chilling treatment for $7 \mathrm{~d}, \mathrm{H}_{2} \mathrm{O}_{2}$ content was $28.70 \%$ and $21.82 \%$ higher in WBDg 17 and WBD128 than the control, respectively. Accordantly, $\mathrm{O}_{2}$ contents were significantly increased in both genotypes, particularly in WBDg17 (by $76.86 \%$ for WBDg 17 and $49.98 \%$ for WBD128). Similar result was also obtained by nitro blue tetrazolium chloride staining (Supplemental Fig. 2). These results showed that the cold-induced ROS concentration was higher in WBDg17. Anti- $\mathrm{O}_{2}^{-}$activity was used to evaluate the activity of scavenging superoxide anion in the study. As shown in Fig. $2 \mathrm{C}$, chilling stress increased the activities of anti- $\mathrm{O}_{2}^{-}$in both genotypes, and to a greater extent in WBD128.

Changes in ANTIOXIDANT ACTIVITY UNDER CHILling STRESS. As shown in Fig. 3A, chilling treatment dramatically increased GSH content by $49.29 \%$ and $210.74 \%$ for WBDg 17 and WBD128, respectively. Similarly, total glutathione content was $97.18 \%$ and $177.54 \%$ higher for WBDg17 and WBD128 than the control, respectively (Fig. 3C). Although the contents of GSSG were increased in both genotypes by chilling exposure (by $153.03 \%$ for WBDg17 and $142.11 \%$ for WBD128), the level in WBD128 was lower than that in WBDg17 (Fig. 3B). Furthermore, chilling stress decreased the GSH/GSSG ratio by $119.18 \%$ in $\operatorname{WBDg} 17$, but increased the value by $16.64 \%$ in WBD128 (Fig. 3D).

CHANGES IN FATTY ACID COMPOSITION UNDER CHILLING STRESS. In the present study, four major fatty acids were identified and quantified. There were two SFAs, including palmitic acid (C16:0) stearic acid (C18:0), and two UFAs, containing linoleic acid (C18:2) and linolenic acid (C18:3). As shown in Fig. 4, the palmitic acid content was $16.46 \%$ in WBDg 17 and $20.10 \%$ in WBD128 under control condition. However, after chilling stress exposure the percentages were $21.79 \%$ and $19.97 \%$ in WBDg17 and WBD128, respectively (Fig. 4A). The stearic
A
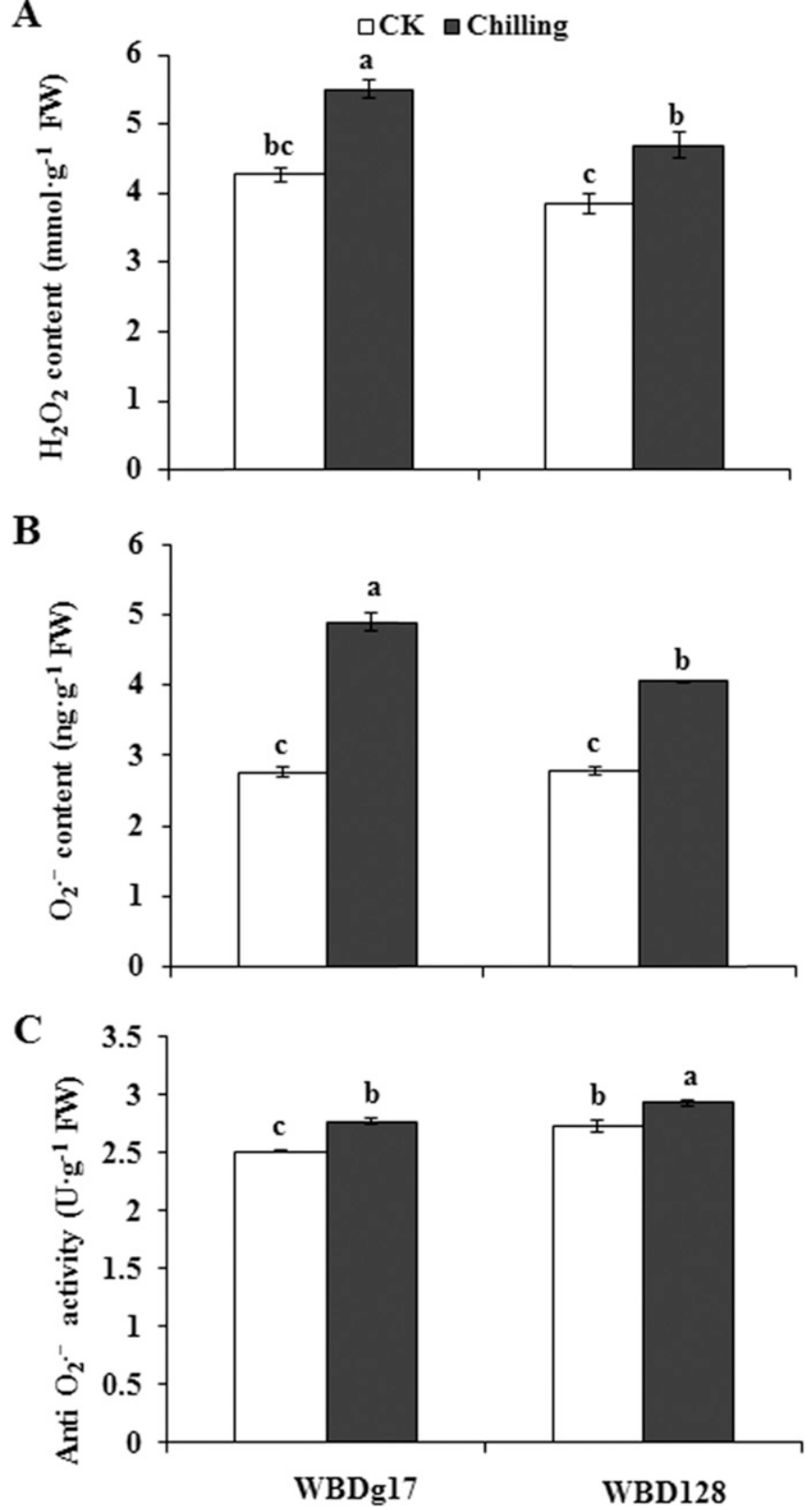

Fig. 2. Changes of (A) $\mathrm{H}_{2} \mathrm{O}_{2}$ content, (B) $\mathrm{O}_{2}{ }^{-}$content, and (C) anti- $\mathrm{O}_{2}{ }^{-}$activity in cold-sensitive genotype WBDg17 and cold-resistant bermudagrass genotype WBD128 under chilling stress. CK was the control with (light/dark) 12/ $12 \mathrm{~h}$ and $30 / 25^{\circ} \mathrm{C}$. Chilling represented (light/dark) $12 / 12 \mathrm{~h}$ and $4 / 4{ }^{\circ} \mathrm{C}$ conditions. All the regimes were treated for $7 \mathrm{~d}$. The FW was fresh weight. Mean values and SD were calculated from three biological repeats. Different letters represented statistical difference significant among different regimes by Duncan's multiple range tests $(P<0.05)$.

acid content was increased from $5.22 \%$ to $6.8 \%$ in WBDg 17 by end of $7 \mathrm{~d}$ of chilling treatment (Fig. 4B). In WBD128, a minor increase from $5.32 \%$ to $6.06 \%$ was observed. In absence of chilling stress, the linoleic acid (C18:2) accounted for $7.38 \%$ and $13.06 \%$ of total fatty acid content in WBDg17 and WBD128, respectively. After $7 \mathrm{~d}$ of chilling treatment, the linoleic acid contents were $2.37 \%$ in WBDg 17 and $8.54 \%$ in WBD128 (Fig. 4C). As for C18:3, the content was $70.50 \%$ in WBDg17 and $61.52 \%$ in WBD128 under control condition. 

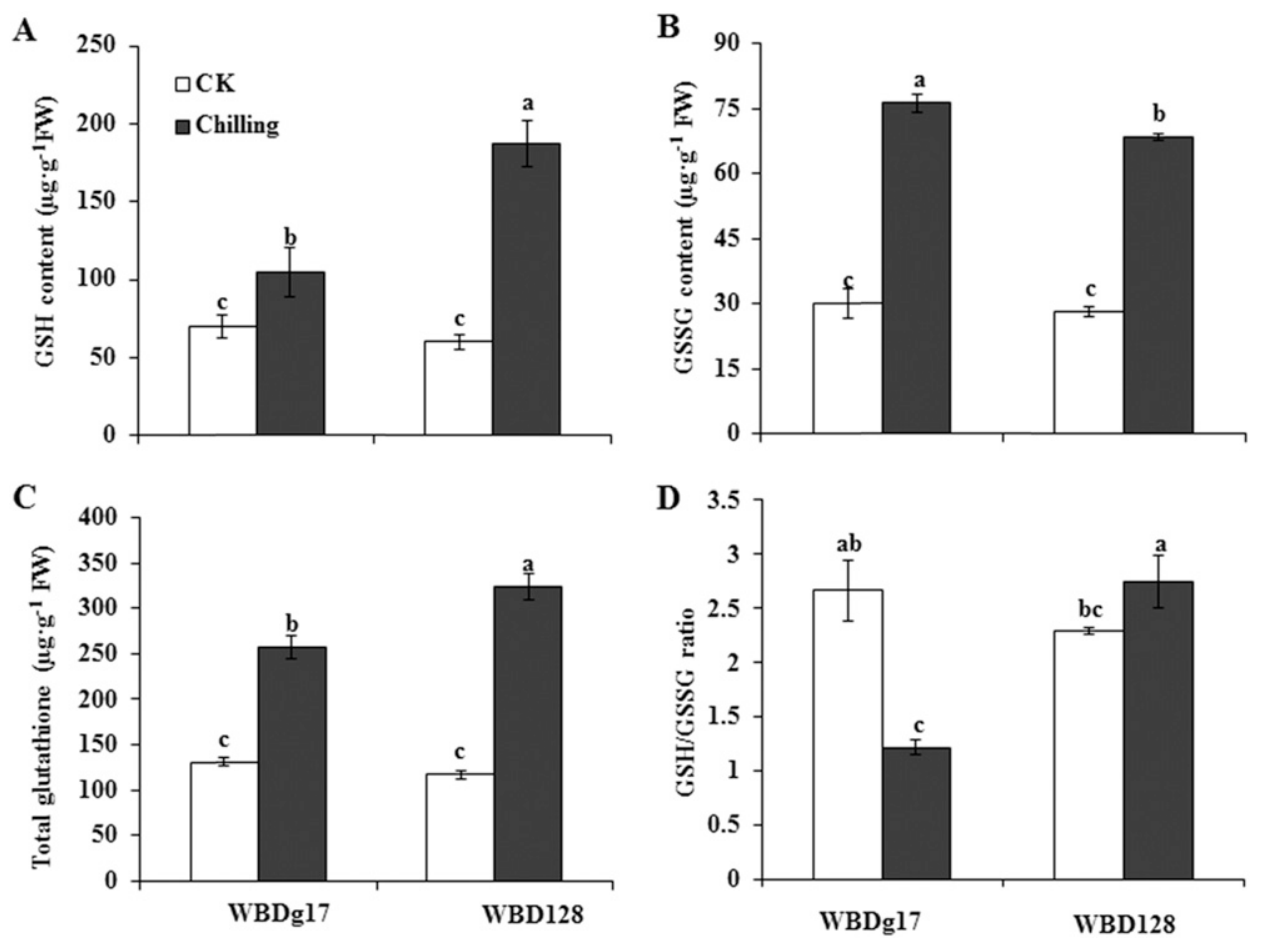

Fig. 3. Changes of (A) reduced glutathione (GSH) content, (B) oxidized glutathione (GSSG) content, (C) total glutathione content, and (D) GSH/GSSG ratio in cold-sensitive genotype WBDg17 and coldresistant bermudagrass genotype WBD128 under chilling stress. CK was the control with (light/dark) 12/ $12 \mathrm{~h}$ and $30 / 25^{\circ} \mathrm{C}$. Chilling represented (light/dark) $12 / 12 \mathrm{~h}$ and $4 / 4{ }^{\circ} \mathrm{C}$ conditions. All the regimes were treated for $7 \mathrm{~d}$. The FW was fresh weight. Mean values and SD were calculated from three biological repeats. Different letters represented statistical difference significant among different regimes by Duncan's multiple range tests $(P<0.05)$.
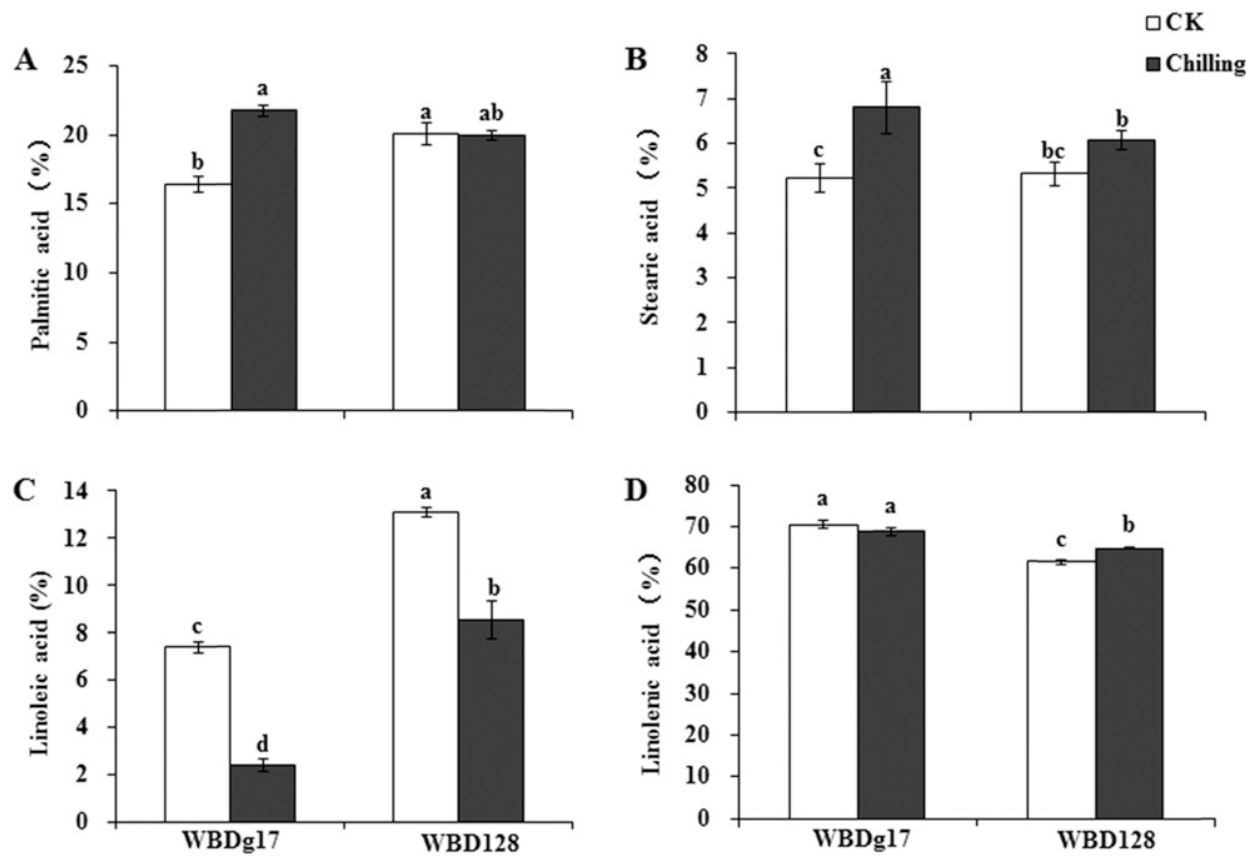

Fig. 4. Changes of four major fatty acids [(A) palmitic acid, (B) stearic acid, (C) linoleic acid, and (D) linolenic acid] compositions in cold-sensitive genotype WBDg17 and cold-resistant bermudagrass genotype WBD128 under chilling stress. CK was the control with (light/dark) $12 / 12 \mathrm{~h}$ and $30 / 25^{\circ} \mathrm{C}$. Chilling represented (light/ dark) $12 / 12 \mathrm{~h}$ and $4 / 4{ }^{\circ} \mathrm{C}$ conditions. All the regimes were treated for $7 \mathrm{~d}$. Mean values and SD were calculated from three biological repeats. Different letters represented statistical difference significant among different regimes by Duncan's multiple range tests $(P<0.05)$.
However, chilling treatment decreased the percentages to $68.69 \%$ in WBDg 17 , inversely, increased to $64.85 \%$ in WBD128 (Fig. 4D).

The degree of unsaturation was $77.88 \%$ in WBDg 17 and $74.58 \%$ in WBD128 under control conditions (Fig. 5A). Under chilling stress, the level was decreased by $8.67 \%$ in WBDg17 but almost unaltered in WBD128. To explore further the difference in fatty acid composition between the two genotypes, the UFA/SFA ratio was calculated. In absence of chilling stress, the UFA/ SFA ratio was higher for WBDg17 than that of WBD128 (Fig. 5B). Chilling treatment significantly decreased the value by $30.20 \%$ for WBDg17, whereas had no notable effects in WBD128. Consequently, WBD128 had a higher level of UFA/SFA ratio than WBDg 17 . Similarly, chilling stress decreased the DBI value by $6.78 \%$ for WBDg17, whereas there was no obvious difference in the value for WBD128 (Fig. 5C). These results suggested that maintenance of higher total UFAs composition, particularly linoleic acid, maybe superior prerequisite for superior chilling tolerance in WBD128.

GENE EXPRESSION OF CULTIVAR VARIATION IN RESPONSE TO CHILLING STRESS. To explore further the differences in gene expression pattern of the two genotypes response to chilling stress, we analyzed the expression of several genes. In the present study, an increase in transcripts of $C B F 1$ was observed in both genotypes after chilling treatment at $4{ }^{\circ} \mathrm{C}$ (Fig. 6A). In WBD128, the expression of $C B F 1$ reached peak at $6 \mathrm{~h}$ of chilling treatment, whereas at $24 \mathrm{~h}$ in WBDg17. The peak value for WBD128 was significantly higher than that for WBDg17. Thereafter, levels of $C B F 1$ expression in both genotypes declined to lower level, which was 3 -fold higher than the control level for WBDg17 and 2-fold for WBD128.

A relatively slow upregulation of $L E A$ at $24 \mathrm{~h}$ of chilling treatment was observed in WBDg17 (Fig. 4D). Differently, the expression of LEA in WBD128 rapidly declined at $3 \mathrm{~h}$ of chilling treatment, then substantially increased and reached 

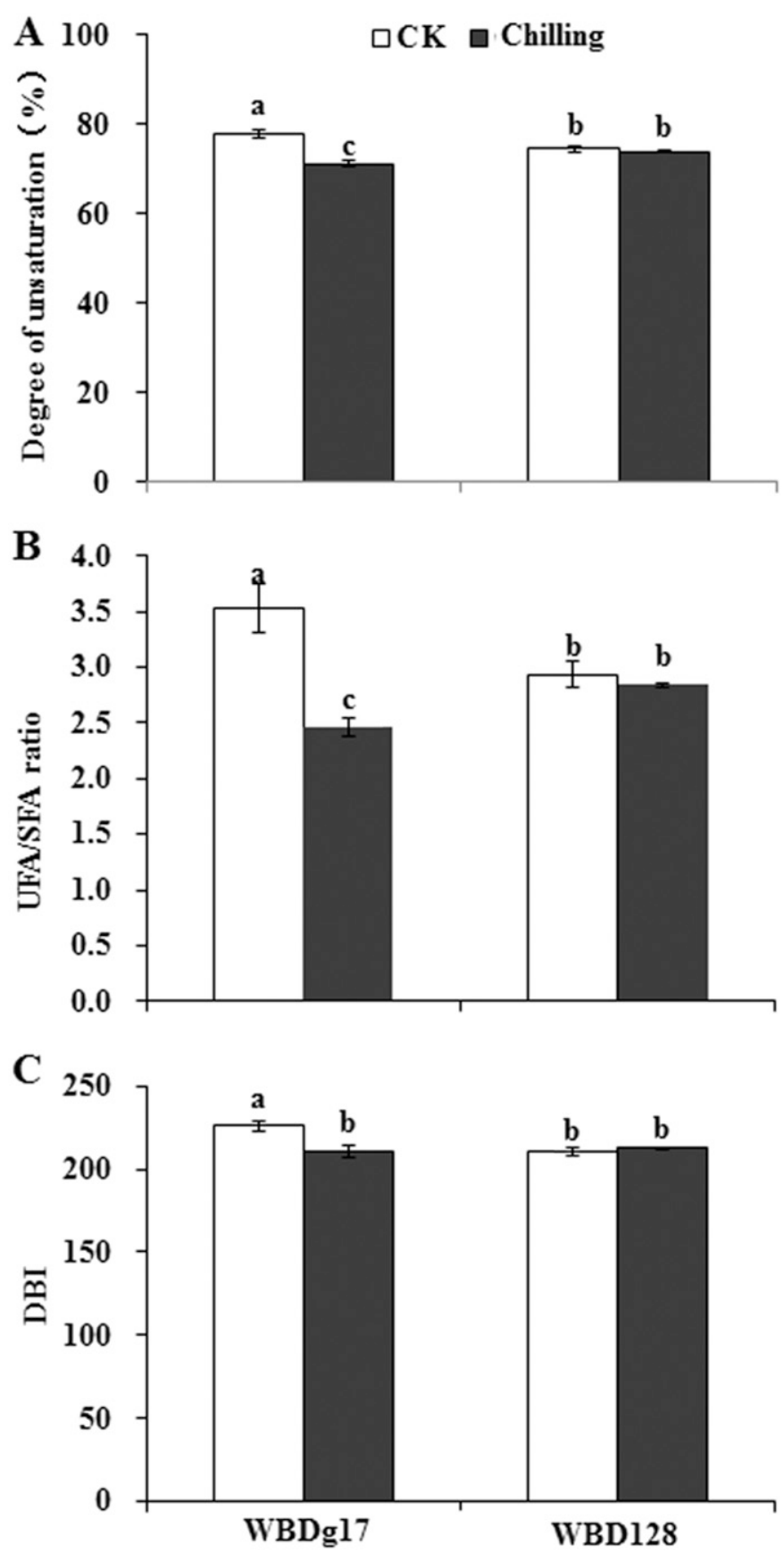

Fig. 5. Changes of (A) degree of unsaturation, (B) the ratio of unsaturated fatty acid (UFA) to saturated fatty acid (SFA), and (C) double bond index (DBI) in cold-sensitive genotype WBDg17 and cold-resistant bermudagrass genotype WBD128 under chilling stress. CK was the control with (light/dark) $12 / 12 \mathrm{~h}$ and $30 / 25{ }^{\circ} \mathrm{C}$. Chilling represented (light/dark) $12 / 12 \mathrm{~h}$ and $4 / 4{ }^{\circ} \mathrm{C}$ conditions. All the regimes were treated for $7 \mathrm{~d}$. Mean values and SD were calculated from three biological repeats. Different letters represented statistical difference significant among different regimes by Duncan's multiple range tests $(P<0.05)$.

peak at $6 \mathrm{~h}$, thereafter decreased to the control level (Fig. 5B). The level of $L E A$ expression was significantly higher in WBD128 at $0,3,6$, and $48 \mathrm{~h}$.

In addition, two genes encoding antioxidant enzymes were analyzed. Generally, chilling stress induced both $\mathrm{Cu} / \mathrm{Zn} S O D$ and $P O D-2$ transcriptions. In WBDg17, expression of $\mathrm{Cu} / \mathrm{Zn}$ $S O D$ rapidly increased and reached the peak at $3 \mathrm{~h}$ of chilling treatment, which was 3-fold higher than the control. Thereafter, the expression declined from 6 to $24 \mathrm{~h}$, and maintained at a relatively lower level at $48 \mathrm{~h}$. However, in WBD128, a slight increase of $\mathrm{Cu} / \mathrm{Zn} S O D$ expression was observed from 3 to $6 \mathrm{~h}$ of chilling treatment, then decreased from 12 to $24 \mathrm{~h}$, and finally increased mildly at $48 \mathrm{~h}$. Compared with the cold-sensitive genotype, $\mathrm{Cu} / \mathrm{Zn}$ SOD transcription in WBD128 was significantly lower at $3,6,12$, and 24 h of chilling treatment, whereas higher at 24 and $48 \mathrm{~h}$. Similarly, in both genotypes, chilling dramatically induced $P O D-2$ expression at $3 \mathrm{~h}$, and eventually declined to the least level at $6 \mathrm{~h}$, then up-regulated at $12 \mathrm{~h}$, and finally declined moderately at 24 to $48 \mathrm{~h}$. Comparison of $P O D-$ 2 expression in the two genotypes revealed higher expression in WBD128 than that in WBDg17 at 3, 24, and $48 \mathrm{~h}$.

\section{Discussion}

Low temperature is one of the most detrimental environmental stresses, which can induce cell damage and restrain plant growth (Catalá et al., 2014; Shi et al., 2012; Yang et al., 2006). The mechanisms of chilling stress injury are exceedingly complex, and the causes of injury are not clearly understood. To resist cold stress, multiple changes occur in plant, which include membrane stability, enzymes activity, gene expression, and metabolism (Fan et al., 2014; Hu et al., 2016a; Shi et al., 2014). During evolutionary process, plants have acquired adaptive responses to survive extreme temperatures. Many plants from temperate regions increase in freezing tolerance upon exposure to low, nonfreezing temperatures, which is a phenomenon known as cold acclimation (Thomashow, 1999). The process of cold acclimation is extremely complex, which involves numerous physiological and biochemical changes, such as alterations in fatty acid composition and the accumulation of sugars, amino acid, and other osmolytes (Catalá et al., 2014). Bermudagrass, an important warm-season turfgrass species, may take at least 3 to 4 weeks to complete cold acclimation process, and it may experience a short period of chilling stress in late fall and early spring in some regions.

RWC, a vital indicator of the internal water status of plant, is used to evaluate the hydration state or internal water deficit degree in plant during dehydration (Rachmilevitch et al., 2006). In the present study, low temperature decreased the RWC in both genotypes, particularly in WBDg17. Our results indicated that WBD128 had significantly higher internal water status, which can be beneficial by providing a suitable internal environment for physiological function in plants (Fig. 1).

As one of the major environmental stresses, cold stress causes oxidative stress by rapid and excessive production of ROS. As observed in Fig. 2, chilling treatment dramatically increased $\mathrm{H}_{2} \mathrm{O}_{2}$ and $\mathrm{O}_{2}^{-}$contents in both genotypes, and the levels were significantly higher in WBDg17. Meanwhile, the activities of anti $\mathrm{O}_{2}^{-}$were enhanced by low temperature in both genotypes, especially for WBD128. Luo et al. (1997) indicated that the injury is mitigated when activity of scavenging superoxide anion is enhanced in plants exposed to adverse environmental stress. Our result was consistent with Jeon et al. (2010), Hu et al. (2013), and Shi et al. (2014). Plants have evolved complicated antioxidant defense systems to efficiently eliminate excessive ROS, enzymatic antioxidants and nonenzymatic antioxidants are the high-efficiency ways to protect plant from ROS damage (Apel and Hirt, 2004; Mittler, 2002). In our previous study, chilling treatment significantly induced activities of SOD, POD, ascorbate peroxidase (APX), and GS 


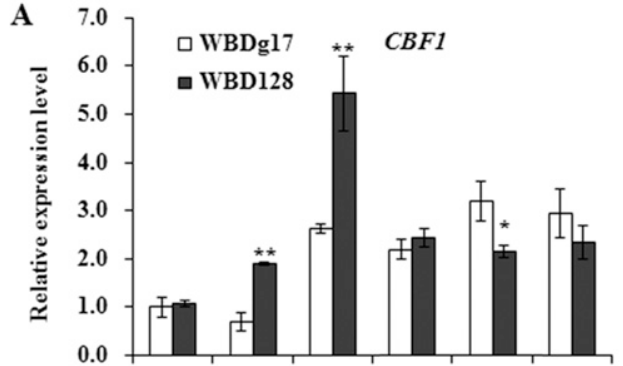

B
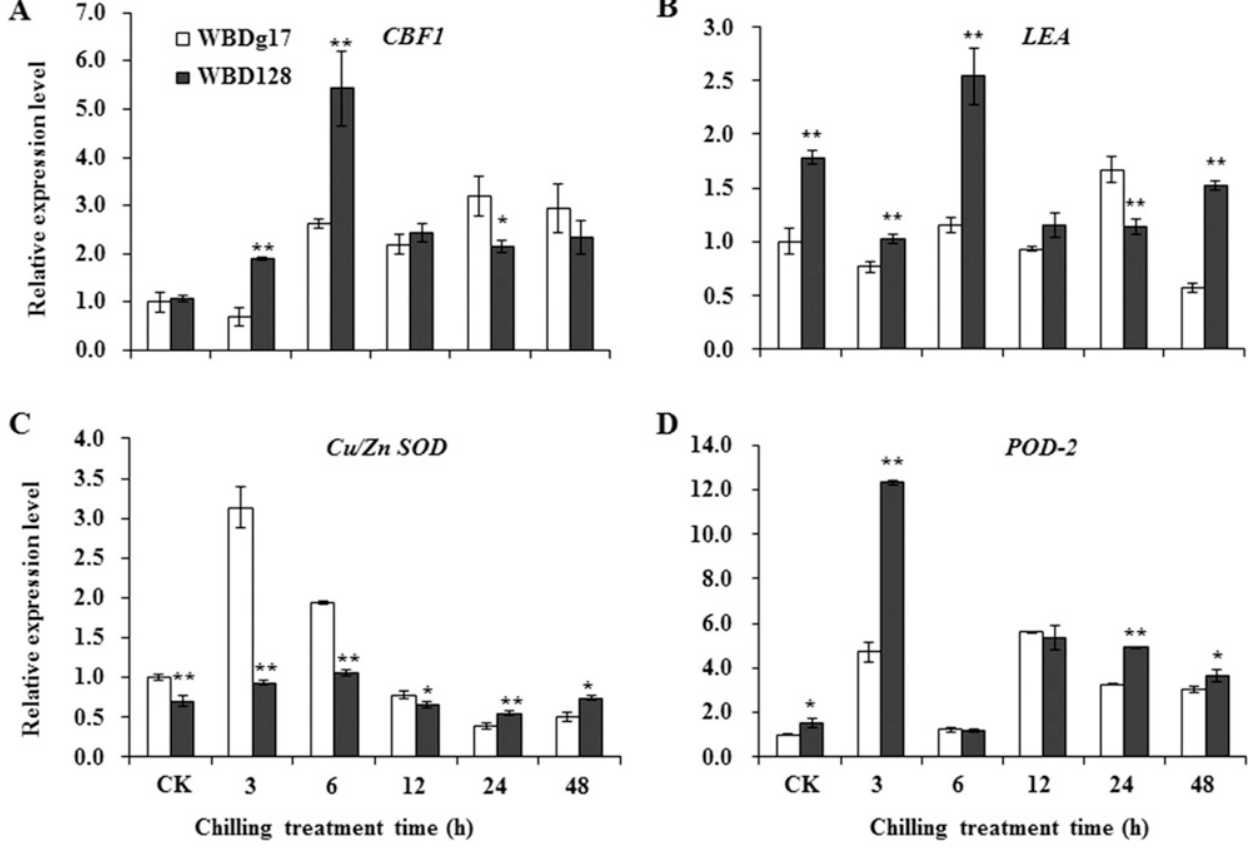

D

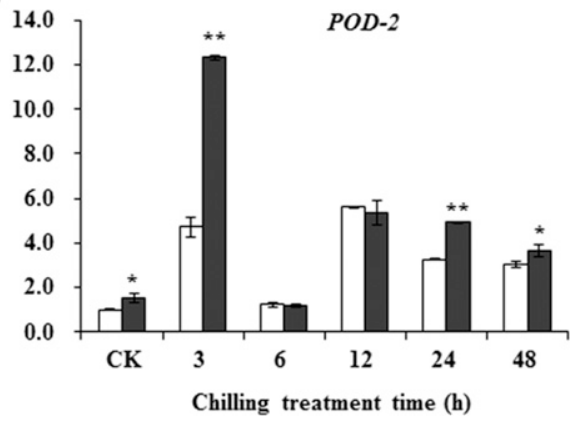

Fig. 6. Changes of (A) relative expression of gene that encodes one kind of C-repeat-binding factor/DRE-binding factor $(C B F 1),(\mathbf{B})$ late embryogenesis abundant proteins $L E A,(\mathbf{C})$ superoxide dismutase $C u / Z n S O D,(\mathbf{D})$ and peroxidase $P O D-2$ in cold-sensitive genotype WBDg17 and cold-resistant bermudagrass genotype WBD128 under chilling stress. CK was the control with (light/dark) $12 / 12 \mathrm{~h}$ and $30 / 25^{\circ} \mathrm{C}$. Chilling represented (light/ dark) $12 / 12 \mathrm{~h}$ and $4 / 4{ }^{\circ} \mathrm{C}$ conditions. All the regimes were treated for $7 \mathrm{~d}$. Total RNA were isolated from leaves treated at $4{ }^{\circ} \mathrm{C}$ for $0,3,6,12,24$, and $48 \mathrm{~h}$, respectively. Quantitative real time polymerase chain reaction was repeated for three times. Columns marked with star indicated statistical significance between WBDg17 and WBD128 based on independent-samples $t$ test.

transferase in bermudagrass (Hu et al., 2016a, 2016b). GSH has been reported to react chemically with ROS, which functions as free radical scavenger and is vital for cellular defense against ROS (Şahin and Gümüşlü, 2004). A high ratio of GSH to GSSG is conducive to improved chilling tolerance (Kocsy et al., 2001). Walker and Mckersie (1993) indicated that the GSH content and the GSH/GSSG ratio were significantly higher in tolerant genotypes of tomato (Solanum lycopersicum), than that in sensitive ones at low temperature. Consistently, WBD128 had remarkably higher GSH content and GSH/GSSG ratio under chilling condition (Fig. 3), suggesting more prominent ROS detoxification in WBD128, due to elevated level of GSH activity and lower level of ROS content.

SOD catalyzes the process of converting two superoxide radicals $\left(\mathrm{O}_{2}^{-}\right)$to $\mathrm{H}_{2} \mathrm{O}_{2}$ and $\mathrm{O}_{2}$, including $\mathrm{Cu} / \mathrm{Zn} \mathrm{SOD}, \mathrm{Mn}-\mathrm{SOD}$, as well as Fe-SOD (Alscher et al., 2002). These isoenzymes have different molecular structures but catalyze the same reaction process. Thereafter, the $\mathrm{H}_{2} \mathrm{O}_{2}$ was removed by APX, POD, GPX resulting in production of $\mathrm{H}_{2} \mathrm{O}$ and $\mathrm{O}_{2}$ (Apel and Hirt 2004; Foyer et al., 1997; Mittler, 2002). Increased expression of antioxidant systems has been suggested to render protection from oxidative stress caused by cold stress (Baek and Skinner, 2003). In the study, chilling stress increased the contents of $\mathrm{O}_{2}^{-}$in both genotypes, so the level of $\mathrm{O}_{2}^{-}$in WBD128 is found to be higher than control (Fig. 2B). Meanwhile, chilling stress significantly induced $\mathrm{Cu} / \mathrm{Zn} S O D$ expression in WBDg17 (Fig. 6C), but the $\mathrm{O}_{2}^{-}$content in WBD128 was not very low compared with WBDg17 (Fig. 2B), which might be attributed to the complicated interactions of SOD isoenzymes. Different results were observed in the study of wheat (Triticum aestivum). Baek and Skinner (2003) indicated that lower levels of $C u / Z n S O D$ and $M n S O D$ were observed in NIL 443 (spring wheat) compared with NIL 442 (winter wheat) after cold treatment. The different expression patterns of bermudagrass and wheat may be related to species specificity. Moreover, the elevated extent of $P O D-2$ expression induced by chilling stress was higher for WBD128 (Fig. 6D). It might be due to more severe damage to WBDg17 that resulted in higher level of superoxide radicles. Eventually, accumulation of superoxide radicles induced higher level of SOD gene expression to withstand low temperatureinduced oxidative stress. Relatively lower levels of superoxide radicals in WBD128, while higher $P O D$ expression, contributed to the removal of $\mathrm{H}_{2} \mathrm{O}_{2}$, which further enhanced the chilling tolerance in bermudagrass.

The C-repeat-binding factor/ dehydration responsive element binding factor (CBF/DREB) pathway has been considered as a principal mechanism of cold response in plant (Thomashow, 1999). Among this pathway, CBF can activate numerous downstream coldregulated $(C O R)$ genes, which can render plant resistance to cold stress. In the study, the level of $C B F 1$ expression induced by chilling stress was generally higher for WBD128 than that for WBDg17 (Fig. 6A). The result revealed that the more rapidly and greater increase of $C B F 1$ expression may activate more COR genes transcription in WBD128, which is beneficial to enhance resistance to chilling stress. LEA has been confirmed to play a crucial role in plant response to cold stress, especially for stabilization of cell membrane (Tunnacliffe and Wise, 2007). In this study, the generally lower level of $L E A$ expression in WBDg17 can lead to less accumulation of LEA protein, which may contribute to enhance the sensitivity to chilling stress (Fig. 6B).

Biological membrane is considered as a primary target site for destruction by cold stress (Cyril et al., 2002), whereas electrolyte leakage (EL) and malondialdehyde (MDA) are the typical indicators to evaluate the integrity of cell membrane. In our previous studies, chilling treatment significantly increased the values EL and MDA in both genotypes, and to a higher extent in WBDg 17 (Hu et al., 2016a, 2016b). To further explore the possible mechanism underlying membrane peroxide, the lipid composition was analyzed. It has been determined that there are changes in lipid composition of membranes when plants are exposed to cold stress (Cyril et al., 2002; Vigh et al., 1998). Sufficient evidence indicate that the biophysical state of cellular membrane, mainly composed of two lipid bilayers, is pivotal for maintaining membrane integrity under cold stress (Vigh et al., 1998). It has been postulated that the primary cold injury results from membrane lipid transition from fluid phase to gel phase (Lyons, 1973). Different with SFAs, UFAs are 
arranged loosely in the lipid bilayers, which results from the nonlinearity of the fatty acid arrangement introduced by double bonds (Lehninger, 1977). It has been reported that a positive association of UFA content and membrane fluidity is vital for proper cellular metabolism and biological function under environmental stresses (Hoekstra et al., 2001). During chilling exposure, UFAs are vital for maintaining membrane fluidity. This might be attributed to the function of lowering the transition temperature, partly by introducing bends in the linear fatty acyl chains (Cyril et al., 2002). This protects the acyl chains of adjacent lipids from tight packing, which is beneficial for maintaining molecular interactions (Cyril et al., 2002). In the present study, as observed for the two SFAs, chilling stress remarkably increased palmitic acid (16:0) and stearic acid (C18:0) proportions of total lipid in the WBDg17, whereas had no significant effects on the two lipids proportion in WBD128 (Fig. 4A and B). Increase of $\mathrm{C} 16: 0$ and $\mathrm{C} 18: 0$ relative contents indicated that the membrane rigidity is enhanced in WBDg17, which results from linearity of lipid arrangement in cell membrane phospholipid phase (Cyril et al., 2002; Lehninger 1977). This result was consistent with the study of Zhong et al. (2011). Compared with WBDg17, the lower percentage and minor change of SFAs might have contributed toward maintenance of cell membrane liquidity in WBD128.

The percentages of linoleic acid (C18:2) was higher in WBD128 than that in WBDg17 under normal condition (Fig. 4C). After $7 \mathrm{~d}$ of chilling treatment, the percentages decreased in both genotypes, and WBD128 had a significantly higher level of linoleic acid. For linolenic acid, chilling stress observably induced the rise of percentage in WBD128, whereas there was no obvious change in WBDg17 (Fig. 4D). These results suggested that the biosynthesis of linolenic acid might be regulated in plant response to chilling stress. The process of linolenic acid synthesis is complex and catalyzed by a battery of desaturase enzymes. First, stearoyl-acyl-carrierprotein (ACP) desaturase converts stearic acid to oleic acid (C18:1). Then C18:1 is catalyzed to form linoleic acid (C18:2) by oleoyl-phosphatidylcholine (PC) desaturase. Finally, the formation of linolenic acid (C18:3) is carried out by linoleoylPC desaturase (Cyril et al., 2002). On the basis of the observed results, we hypothesized that the activities of desaturases may be regulated by chilling stress. DBI, an indicator for evaluating unsaturation level of fatty acids (Zhong et al., 2011), was applied in the present study. Under chilling condition, the value of DBI declined in WBDg17, whereas there was no significant change in WBD128 (Fig. 5). Similar results were observed in the parameters of UFA/SFA ratio and degree of unsaturation. In addition, values of the two indicators were higher in WBD128 than that in WBDg17. These results further suggested that relatively higher unsaturation percentage of total lipid may have contributed to the greater chilling resistance in WBD128.

\section{Conclusion}

The mechanism in bermudagrass response to chilling stress is complex. Superior resistance to low temperature in WBD128 may be mainly related to greater response of antioxidant defense system and relatively higher proportion of UFAs. They are jointly conducive for stability maintenance and integrity of membrane to sustain normal functions, thus to enhance chilling resistance in bermudagrass.

\section{Literature Cited}

Allen, R.D. 1995. Dissection of oxidative stress tolerance using transgenic plants. Plant Physiol. 107:1049 (abstr.).

Alscher, R.G., N. Erturk, and L.S. Heath. 2002. Role of superoxide dismutases (SODs) in controlling oxidative stress in plants. J. Expt. Bot. 53:1331-1341.

Apel, K. and H. Hirt. 2004. Reactive oxygen species: Metabolism, oxidative stress, and signal transduction. Annu. Rev. Plant Biol. 55:373-399.

Arora, A., R.K. Sairam, and G.C. Srivastava. 2002. Oxidative stress and antioxidative system in plants. Curr. Sci. 82:1227-1238.

Baek, K.H. and D.Z. Skinner. 2003. Alteration of antioxidant enzyme gene expression during cold acclimation of near-isogenic wheat lines. Plant Sci. 165:1221-1227.

Barrs, H. and P. Weatherley. 1962. A re-examination of the relative turgidity technique for estimating water deficits in leaves. Austral. J. Biol. Sci. 15:413-428.

Burke, M.J., L.V. Gusta, H.A. Quamme, C.J. Weiser, and P.H. Li. 1976. Freezing and injury in plants. Annu. Rev. Plant Physiol. 27:507-528.

Catalá, R., R. López-Cobollo, M.M. Castellano, T. Angosto, J.M. Alonso, J.R. Ecker, and J. Salinas. 2014. The Arabidopsis 14-3-3 protein RARE COLD INDUCIBLE 1A links low-temperature response and ethylene biosynthesis to regulate freezing tolerance and cold acclimation. Plant Cell 26:3326-3342.

Chen, L., F. Ren, H. Zhong, W. Jiang, and X. Li. 2010. Identification and expression analysis of genes in response to high-salinity and drought stresses in Brassica napus. Acta Biochim. Biophys. Sin. (Shanghai) 42:154-164.

Cyril, J., G.L. Powell, R.R. Duncan, and W.V. Baird. 2002. Changes in membrane polar lipid fatty acids of seashore paspalum in response to low temperature exposure. Crop Sci. 42:2031-2037.

Fagerness, M.J., F.H. Yelverton, D.P. Livingston, and T.W. Rufty. 2002. Temperature and trinexapac-ethyl effects on bermudagrass growth, dormancy, and freezing tolerance. Crop Sci. 42:853-858.

Fan, J., J. Ren, W. Zhu, E. Amombo, J. Fu, and L. Chen. 2014. Antioxidant responses and gene expression in bermudagrass under cold stress. J. Amer. Soc. Hort. Sci. 139:699-705.

Foyer, C.H., H. Lopez-Delgado, J.F. Dat, and I.M. Scott. 1997. Hydrogen peroxide and glutathione associated mechanisms of acclamatory stress tolerance and signaling. Physiol. Plant. 100:241-254.

Halliwell, B. and J.M. Gutteridge. 2015. Free radicals in biology and medicine. Oxford Univ. Press, Oxford, UK.

Hoagland, D.R. and D.I. Arnon. 1950. The water-culture method for growing plants without soil. California Agr. Expt. Sta. Circ. 347.

Hoekstra, F.A., E.A. Golovina, and J. Buitink. 2001. Mechanisms of plant desiccation tolerance. Trends Plant Sci. 6:431-438.

$\mathrm{Hu}, \mathrm{Z}$., J. Fan, K. Chen, E. Amombo, L. Chen, and J. Fu. 2016a. Effects of ethylene on photosystem II and antioxidant enzyme activity in bermuda grass under low temperature. Photosynth. Res. 128:59-72.

Hu, Z., J. Fan, Y. Xie, E. Amombo, A. Liu, M.G. Mukami, L. Chen, and J. Fu. 2016b. Comparative photosynthetic and metabolic analyses reveal mechanism of improved cold stress tolerance in bermudagrass by exogenous melatonin. Plant Physiol. Biochem. 100:94-104.

Hu, Y., L. Jiang, F. Wang, and D. Yu. 2013. Jasmonate regulates the inducer of $\mathrm{CBF}$ expression-c-repeat binding factor/DRE binding factorl cascade and freezing tolerance in Arabidopsis. Plant Cell 25:2907-2924.

Iswari, S. and J.P. Palta. 1989. Plasma membrane ATPase activity following reversible and irreversible freezing injury. Plant Physiol. 90:1088-1095.

Jeon, J., N.Y. Kim, S. Kim, N.Y. Kang, O. Novák, S.J. Ku, C. Cho, D.J. Lee, E.J. Lee, M. Strnad, and J. Kim. 2010. A subset of cytokinin two-component signaling system plays a role in cold temperature stress response in Arabidopsis. J. Biol. Chem. 285:23371-23386. 
Kocsy, G., G. Galiba, and C. Brunold. 2001. Role of glutathione in adaptation and signalling during chilling and cold acclimation in plants. Physiol. Plant. 113:158-164.

Kumari, P., A.J. Bijo, V.A. Mantri, C.R.K. Reddy, and B. Jha. 2013. Fatty acid profiling of tropical marine macroalgae: An analysis from chemotaxonomic and nutritional perspectives. Phytochemistry $86: 44-56$.

Larkindale, J. and B. Huang. 2004. Changes of lipid composition and saturation level in leaves and roots for heat-stressed and heat acclimated creeping bentgrass (Agrostis stolonifera). Environ. Exp. Bot. 51:57-67.

Lehninger, A.L. 1977. Biochemistry. 2nd ed. Worth Publ., New York, NY.

Luo, L., T. Sun, and Y. Jini. 1997. Accumulation of superoxide radical in wheat leaves under cadmium stress. Acta Scientiae Circumstantiae 18:495-499.

Lyons, J.M. 1973. Chilling injury in plants. Annu. Rev. Plant Physiol. 24:445-466.

Mauch, F. and R. Dudler. 1993. Differential induction of distinct glutathione S-transferases of wheat by xenobiotics and pathogen attack. Plant Physiol. 102:1193-1201.

McKersie, B.D. and S.R. Bowley. 1997. Active oxygen and freezing tolerance in transgenic plants, p. 203-214. In: P.H. Li and T.H.H. Chen (eds.). Plant cold hardiness. Springer, New York, NY.

Mishra, A., M.K. Patel, and B. Jha. 2015. Non-targeted metabolomics and scavenging activity of reactive oxygen species reveal the potential of Salicornia brachiata as a functional food. J. Funct. Foods 13:21-31.

Mittler, R. 2002. Oxidative stress, antioxidants and stress tolerance. Trends Plant Sci. 7:405-410.

Noctor, G., A.C.M. Arisi, L. Jouanin, K.J. Kunert, H. Rennenberg, and C.H. Foyer. 1998. Glutathione: Biosynthesis, metabolism and relationship to stress tolerance explored in transformed plants. J. Expt. Bot. 49:623-647.

Pearce, R.S. and J.H.M. Willison. 1985. Wheat tissues freeze-etched during exposure to extracellular freezing: Distribution of ice. Planta 163:295-303.

Rachmilevitch, S., M. DaCosta, and B. Huang. 2006. Physiological and biochemical indicators for abiotic stress tolerance, p. 321-356. In: B. Huang (ed.). Plant-environment interactions. CRC Press, Boca Raton, FL.

Rennenberg, H. and C. Brunold. 1994. Significance of glutathione metabolism in plants under stress. Prog. Bot. 55:144-156.

Şahin, E. and S. Gümüşlü. 2004. Cold-stress-induced modulation of antioxidant defence: Role of stressed conditions in tissue injury followed by protein oxidation and lipid peroxidation. Intl. J. Biometeorol. 48:165-171.
Shi, Y., S. Tian, L. Hou, X. Huang, X. Zhang, H. Guo, and S. Yang. 2012. Ethylene signaling negatively regulates freezing tolerance by repressing expression of CBF and type-A ARR genes in Arabidopsis. Plant Cell 24:2578-2595.

Shi, H., T. Ye, and Z. Chan. 2013. Exogenous application of hydrogen sulfide donor sodium hydrosulfide enhanced multiple abiotic stress tolerance in bermudagrass (Cynodon dactylon (L). Pers.). Plant Physiol. Biochem. 71:226-234.

Shi, H., T. Ye, B. Zhong, X. Liu, and Z. Chan. 2014. Comparative proteomic and metabolomic analyses reveal mechanisms of improved cold stress tolerance in bermudagrass (Cynodon dactylon (L.) Pers.) by exogenous calcium. J. Integr. Plant Biol. 56:1064-1079.

Steponkus, P.L. 1984. Role of the plasma membrane in freezing injury and cold acclimation. Annu. Rev. Plant Physiol. 35:543-584.

Thomashow, M.F. 1999. Plant cold acclimation: Freezing tolerance genes and regulatory mechanisms. J. Integr. Plant Biol. 50:571-599.

Tunnacliffe, A. and M.J. Wise. 2007. The continuing conundrum of the LEA proteins. Naturwissenschaften 94:791-812.

Vigh, L., B. Maresca, and J.L. Harwood. 1998. Does the membrane's physical state control the expression of heat shock and other genes? Trends Biochem. Sci. 23:369-374.

Walker, M.A. and B.D. Mckersie. 1993. Role of the ascorbateglutathione antioxidant system in chilling resistance of tomato. J. Plant Physiol. 141:234-239.

Weiser, C.J. 1970. Cold resistance and injury in woody plants knowledge of hardy plant adaptations to freezing stress may help us to reduce winter damage. Science 169:1269-1278.

Yang, P., X. Li, Y. Liang, Y. Jing, S. Shen, and T. Kuang. 2006. Proteomic analysis of the response of Liangyoupeijiu (super highyield hybrid rice) seedlings to cold stress. J. Integr. Plant Biol. 48:945-951.

Zhang, X., E. Ervin, C. Waltz, and T. Murphy. 2011a. Metabolic changes during cold acclimation and deacclimation in five bermudagrass varieties: II. Cytokinin and abscisic acid metabolism. Crop Sci. 51:847-853.

Zhang, X., K. Wang, and E.H. Ervin. 2008. Bermudagrass freezing tolerance associated with abscisic acid metabolism and dehydrin expression during cold acclimation. J. Amer. Soc. Hort. Sci. 133:542-550.

Zhang, X., K. Wang, E. Ervin, C. Waltz, and T. Murphy. 2011 b. Metabolic changes during cold acclimation and deacclimation in five bermudagrass varieties. I. Proline, total amino acid, protein, and dehydrin expression. Crop Sci. 51:838-846.

Zhong, D., H. Du, Z. Wang, and B. Huang. 2011. Genotypic variation in fatty acid composition and unsaturation levels in bermudagrass associated with leaf dehydration tolerance. J. Amer. Soc. Hort. Sci. 136:35-40. 


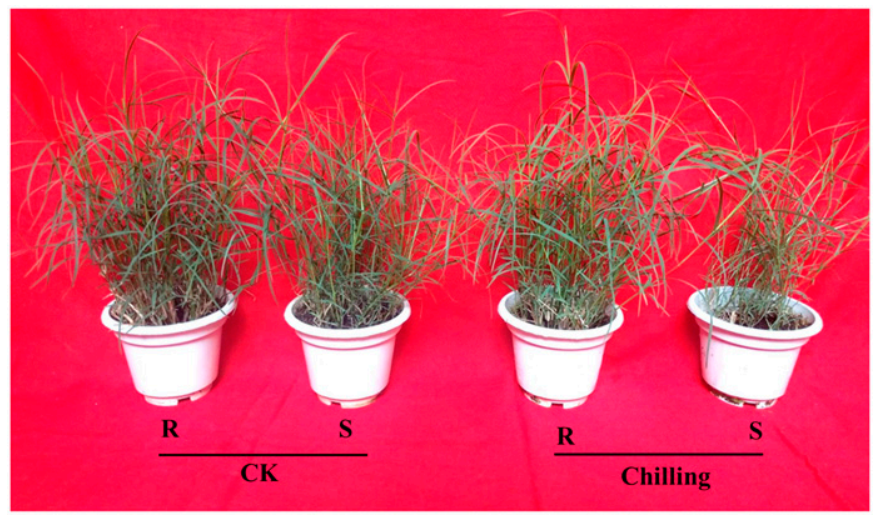

Supplemental Fig. 1. Representative leaves of cold-resistant (R) bermudagrass genotype WBD128 and cold-sensitive (S) genotype WBDg17 under different conditions. CK was the control with (light/dark) $12 / 12 \mathrm{~h}$ and $30 / 25^{\circ} \mathrm{C}$. Chilling represented (light/dark) $12 / 12 \mathrm{~h}$ and $4 / 4{ }^{\circ} \mathrm{C}$ conditions. All the regimes were treated for $7 \mathrm{~d}$.

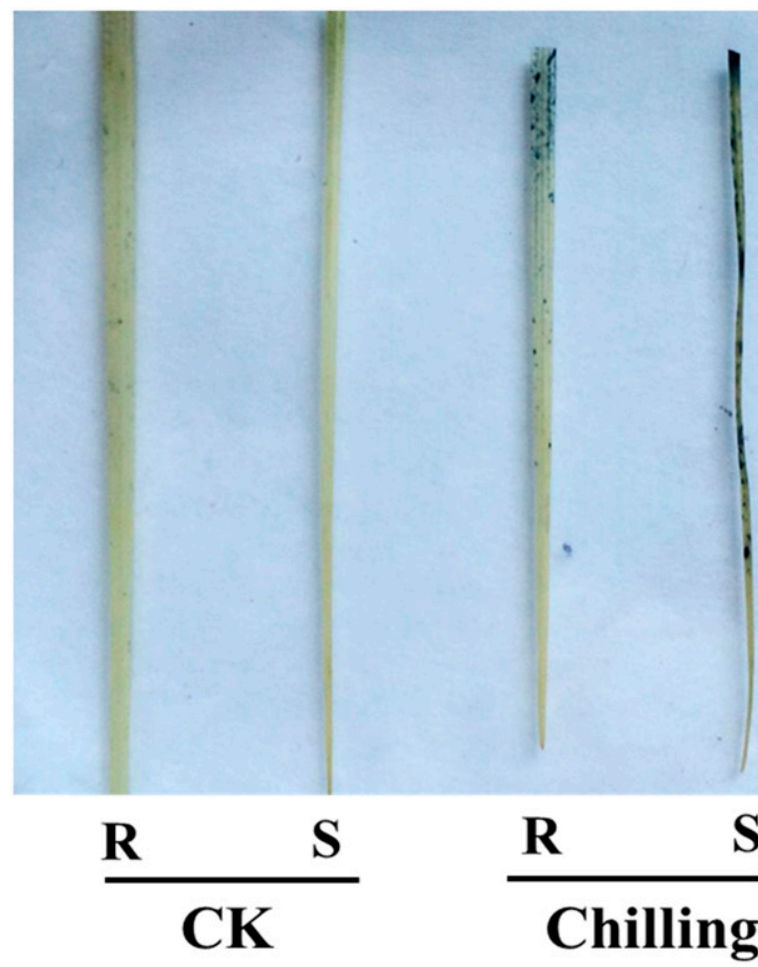

Supplemental Fig. 2. Nitro blue tetrazolium chloride staining images of representative leaves of cold-resistant (R) bermudagrass genotype WBD128 and cold-sensitive (S) genotype WBDg17 under different conditions. CK was the control with (light/dark) $12 / 12 \mathrm{~h}$ and $30 / 25^{\circ} \mathrm{C}$. Chilling represented (light/ dark) $12 / 12 \mathrm{~h}$ and $4 / 4{ }^{\circ} \mathrm{C}$ conditions. All the regimes were treated for $7 \mathrm{~d}$. 